\title{
Individual, Organizational and Emotional Determinants of Teacher Self-Efficacy
}

\author{
Meirav Hen \& Marina Goroshit \\ Tel-Hai Academic College
}

Received: May 24, 2012

Accepted: June 14, 2013

Published: August 1, 2013

doi:10.5296/jse.v3i3.3758

URL: http://dx.doi.org/10.5296/jse.v3i3.3758

\begin{abstract}
Teachers' self-efficacy has been related to teachers' behavior in the classroom and to teacher burnout. Only few studies have examined the ability to influence teachers' self-efficacy or predict it from different angles. The present research aimed to draw together and examine individual, organizational, and emotional variables that may predict teacher self-efficacy, and contribute to our ability to strengthen teachers' beliefs about their capability. Results indicated that emotional self-efficacy and empathy were the strongest predictors of teacher self-efficacy and explained $36 \%$ of its variance. Individual characteristics were the second predictor of teacher self-efficacy and explained $11 \%$ of its variance. Organizational factors were the weakest predictor of teacher self-efficacy ( $1 \%$ of variance). These findings may contribute to the ongoing argument that the focus on teachers' emotions and emotional abilities must grow in order to better the overall educational milieu.
\end{abstract}

Keywords: Teacher self-efficacy 


\section{Introduction}

Teacher self- efficacy is considered one of the key motivation beliefs influencing teachers' professional behaviors and student learning (Gibbs \& Powell, 2011). Over the last 30 years, the volume of teacher self-efficacy research has increased, but questions remain about the direction, quality, and influence resulting from the increased attention given to the construct. Klassen, Tze, Betts \& Gordon ( 2011) in their review of the relevant literature argued that insufficient attention has been paid to the sources and contributors of teachers' self-efficacy , and that our understanding of teacher self- efficacy has suffered as a result. In addition most studies that examined contributors to teacher self-efficacy focused on a specific group of factors, mostly organizational factors . Following their conclusions the present study aimed to draw together and examine individual, organizational, and emotional variables that may predict teacher self-efficacy, and contribute to our ability to strengthen teachers' beliefs about their capability.

\section{Teacher self-efficacy}

Self-efficacy refers to people's judgments of their own capabilities to organize and execute courses of action required to attain designated types of performances (Bandura, 1982). According to Bandura (1986), self -efficacy strongly influences the choices people make, the effort they expend, and their perseverance in the face of challenge. Self-efficacy beliefs influence task choice, effort, persistence, resilience, and achievement (Bandura, 1986; Britner $\&$ Pajares, 2006). Self-efficacy beliefs influence thought patterns and emotions that enable goal-directed actions in situations where people believe they can exercise some control. Selfefficacy is a future-oriented belief about the level of competence a person expects he or she will display in a given situation. High self-efficacy levels enable people to select challenging settings and explore their environment or create new ones. Thus, they represent a belief in one's own competence in dealing with a variety of demands, and can be characterized mainly as being competence-based, prospective, and action-related (Usher \& Pajares, 2008). Given the pivotal role of self-efficacy beliefs in understanding human behavior, Bandura (1997) postulated that people make judgments of their self- efficacy based on the verbal encouragement of important others such as colleagues, supervisors, and administrators (verbal persuasion), the success or failure of others who serve as models (vicarious experiences), perceptions of past experiences (mastery experiences), and the level of emotional and physiological arousal experienced as they anticipate and practice some competence (Skaalvik \& Skaalvik, 2010).

Teacher self-efficacy (TSE) is the confidence teachers have in their individual capability to influence student learning, and it is considered one of the key motivational beliefs influencing professional teacher behavior and student learning (Chan, 2008). A growing body of empirical evidence supports Bandura's (1982) theory that TSE beliefs are related to the effort they invest in teaching, the goals they set, their persistence when things do not go smoothly, and their resilience in the face of setbacks (Tschannen-Moran \& McMaster, 2009). Studies reported by Tschannen-Moran \& Woolfolk Hoy (2001) have repeatedly demonstrated the importance of teacher self-efficacy and its association with a wide range of teaching and 
learning outcomes. These outcomes include teachers' classroom behaviors and effort; their openness to new ideas and willingness to try new methods; their planning and organizational competence, commitment and enthusiasm for teaching; as well as their perseverance in their chosen career (Klassen, et.al, 2011; Skaalvik \& Skaalvik, 2010). In addition, TSE has been shown to influence students' motivation, academic performance and achievements (Skaalvik $\&$ Skaalvik, 2007). There is some evidence that teachers with low levels of self-efficacy may be more likely to use punitive or reactive disciplinary strategies as a means of behavior management (Woolfolk Hoy \& Burke Spero, 2005). They also experience greater difficulties in teaching, and exhibit lower levels of job satisfaction and higher levels of job-related stress, as compared to teachers with higher levels of self-efficacy (Betoret, 2009). Teachers with high self-efficacy levels tend to implement organized instructional strategies, are more open to new teaching methods, and demonstrate more persistence when working with struggling students (Somech \& Drach-Zahavy, 2000).

\section{Factors contributing to teacher self-efficacy}

Studies have identified a variety of external and internal variables that contribute to and affect teacher self-efficacy. According to Guskey \& Passaro (1994), the internal dimension refers to the extent to which teachers believe that they have personal influence, power, and impact on students' learning, whereas the external dimension reflects teachers' perceptions of factors external to their teaching that place limitations on what they can accomplish in class (Ho \& Hau, 2004) .

Tschannen-Moran, Woolfolk Hoy \& Hoy (1998) proposed that TSE judgments are the result of an interaction between an individual's personal weighing of the factors that make teaching difficult and his/her perceptions of personal teaching capabilities on the other. Klassen \& Chui (2010) found that teachers' years of experience showed nonlinear relationships with all three self-efficacy factors, increasing from early career to mid-career and then decreasing later on. Female teachers had lower classroom management self-efficacy, and those teaching young children (in elementary grades and kindergarten) had higher levels of self-efficacy for classroom management. Brouwers, Evers \& Tomic (2001) suggested that high levels of student disruptive behavior engendered a cyclical effect, such that teachers' sense of self-efficacy in the realm of classroom management deteriorated, resulting in high levels of teacher burnout, which in turn led to higher levels of student disruptive behavior, further reducing the teachers' level of self-efficacy. Knobloch \& Whittington (2002) found that collective efficacy, perceived teacher preparation quality, and perceived student teaching experience explained $17 \%$ of the variance in TSE at the 10th week of the school year. Saracaloglu \& Yenice (2009) demonstrated a sufficient change in science teachers' self -efficacy in relation to seniority and weekly lesson load. No sufficient change was found in relation to gender, age, receiving in-service training and job satisfaction. Watson (2006), on the other hand, found that teachers' improved level of self-efficacy after an intense internet workshop remained high even three years after their involvement in the workshop. Tschannen-Moran \& Woolfolk Hoy (2007) suggested that while mastery experience seems to be the main source of teachers' self-efficacy for experienced teachers, contextual factors such as teaching resources and interpersonal support available, were found to be much more 
salient in the self-efficacy beliefs of novice teachers. Further Tschannen-Moran \& McMaster (2009) studied Banduras' sources (verbal persuasion, vicarious experiences, mastery experiences) of teachers' self-efficacy beliefs. Their findings suggested that mastery experiences had the strongest effect on self-efficacy beliefs for reading instruction.

Brouwers, Evers \& Tomic's ( 2001) results showed that teachers' perceived lack of support from colleagues and principals had a significant effect on their self-efficacy beliefs in eliciting support from them, while these self-efficacy beliefs were shown to predict teachers' level of burnout. Friedman (2003) argued that teachers' confidence in their ability to regulate their relationship with students and colleagues contributed the most to their overall sense of self-efficacy in school. Skaalvik \& Skaalvik (2007) found that teachers' self-efficacy levels correlated negatively with time pressures, but correlated positively with feelings of autonomy and relations with parents. Chan $(2003,2004)$ found that interpersonal intelligence predicts teachers' self-efficacy in helping others. Penrose, Perry \& Ball (2007) studied practicing teachers and principals in selected Government schools in Victoria. They found a link between emotional intelligence and teacher self-efficacy. Regression analyses showed that neither gender nor age moderated this relationship. However length of teaching experience and current status added significant direct effects on predicting teacher self -efficacy but did not moderate the relationship between emotional intelligence and teacher self- efficacy. Jennings \& Greenberg (2009) suggested that teachers confident in their ability to recognize emotions and emotional patterns will exhibit higher levels of self-efficacy in teaching. Gibbs (2003) argued that teachers' personal sense of control, and their beliefs in their capability to exercise control of their thinking and feeling, impacts their self-efficacy beliefs and actual teaching.

Recently, Klassen et.al (2011) reviewed teachers' self-efficacy research between the years 1998-2009. They argued that little is known on the sources of TSE and that insufficient attention has been paid to this subject. They found a large number of studies that researched the benefits and contributions of TSE to student academic outcomes and to teachers' behavior and burnout, but very few studies that explored the variables that predict teachers' selfefficacy.

\section{Research questions}

Along these lines and following the above literature, the present study aims to reply on two major questions:

1. How do individual, organizational and emotional variables relate to the teacher self-efficacy?

2. To what extent can teacher self-efficacy be explained by individual, organizational and emotional variables?

We believe that our study, that pulls together different types of variables (internal, external and emotional), may contribute to our ability to better understand and strengthen teachers' beliefs about their capability. Figure 1 summarizes graphically our research model of prediction of teacher self-efficacy by three groups of variables. 


\section{Methods}

\section{Participants and Procedure}

In the current study we used a convenience sample of 620 teachers: $78 \%$ females and $22 \%$ males, with an age range of 22 to 69 years $(M=40.6, S D=11.1)$. Seventy three percent of teachers in the sample described themselves as secular, and the remainder traditional $(17 \%)$ or religious $(9 \%)$. Fifty three percent of subjects graduated from college, 32\% from university and $14 \%$ from teachers' seminar. The range of the duration of teaching experience in the sample was 1 to 42 years $(M=14 ; S D=11)$. The data were collected by research assistants in ten schools in northern and central Israel. The schools were located across a mixed demographic area and were classified as being in either inner city $(70 \%)$ or rural settings $(30 \%)$. The assistants explained to the teachers that the current study concerns attitudes and perceptions of teachers and that participation is voluntary and anonymous. Completing the questionnaire lasted 20 minutes on average. Teachers were not offered any incentive.

\section{Instruments}

Teacher self-efficacy. Teacher self-efficacy (TSE) was measured by a questionnaire that aimed to assess teachers' feelings of self-efficacy (Friedman \& Wax, 2002). The original instrument included 29 items on a 5-point Likert scale (1-"does not describe me at all" to 5 "describes me well") and related to three dimensions: learning tasks ("I think that I am able to be very creative in my work with children"), relationships with students ("I think that my way of teaching has an influence on the values and the principles of my pupils"), communication with the organization ("I am an active member in decision making processes at my school"). The internal reliability of the TSE scale was: $\alpha=.89$, and a general mean score was used.

Individual variables. Individual characteristics included the following: level of religiosity (secular or traditional/religious), job seniority (up to 5 years or five years and more), education (university, college or seminar), and training to work with pupils with learning disabilities (yes or no). Two additional variables - age and gender - were used as control variables.

Organizational variables. Organizational variables were measured by three variables: type of school (high school or primary/junior high school), integration of pupils with learning disabilities in teachers' classroom (yes or no), and number of pupils in a classroom.

Emotional variables. Empathy was measured using a multidimensional empathy questionnaire (Interpersonal Reactivity Index) (Davis, 1983). This instrument contained 28 statements which measured four dimensions. In this study, the questionnaire has been adjusted to school situations by embedding images of teachers and students into the items, for example: "I often see things from the perspective of the student" instead of "...from the perspective of the other" (Chen, 2010). The items were ranked on a 5-point Likert scale (1 "does not describe me at all" to 5 - "describes me well"). The internal reliability of the empathy scale was: $\alpha=84$, and a general mean score was used.

In the emotional self-efficacy (ESE) questionnaire (Kirk, Schutte, \& Hine, 2008), the subjects 
were asked to assess on a 5-point Likert scale, to what extent each item describes (5) or does not describe (1) him/her. This questionnaire included 32 statements representing four dimensions: understanding emotions ("I know what causes to my negative feelings"), perceiving others' emotions ("I am able to recognize other person's negative feelings"), facilitating ("I know how to use positive feelings to produce good ideas"), and regulating emotions ("I am able to change negative feelings to positive ones"). The internal reliability of the ESE scale was: $\alpha=.83$, and a general mean score was used.

Results

To reply on our first research question and to test the relationships between individual, organizational and emotional variables and TSE, we ran bivariate Pearson correlations between the research variables (see Table 1). Table 1 indicates the following: (a) TSE has the highest positive correlations with ESE and empathy: higher ESE and empathy yields higher TSE, (b) TSE is also positively related to age (higher age yields higher TSE reported), (c) traditional or religious subjects, females, experienced primary or junior high school teachers, subjects with special training to work with LD pupils and teachers who integrate LD pupils in their classroom, all reported higher levels of TSE than other subjects.

To answer our second research question according the contribution of each group of variables (individual, organizational and emotional) to the prediction of TSE, as well as the contribution of each variable within a specific group, we ran a three-steps multiple linear regression using forced entry method. The results are shown in Table 2 and Figure 2. At the first step we entered individual variables, at the second-organizational variables, and at the last step - emotional variables. Below we describe in details the results of each step.

First step. Results of the first step showed that the individual variables explained about 11\% of the variation in TSE. The following individual variables predicted TSE significantly: religion (traditional/religious subjects reported higher TSE), job seniority (senior teachers reported higher TSE), training for work with pupils with learning disabilities (teachers who have such training reported higher TSE) and seminar (teachers who studied at seminar, compare to university, reported higher TSE).

Second step. Organizational variables added at the second step, increased the explained variance of TSE by one percent. Although this overall increase was not significant, the school level was found to be a significant predictor of TSE (high school teachers reported lower TSE). The individual variables remained significant after adding organizational variables, suggesting that the latter do not play a role of intervening variables in the relationships between individual variables and TSE.

Third step. At the third step, emotional variables (ESE and empathy) were added to the model. This group of variables increased the explained variance of TSE by 36\%, meaning that emotional variables are the most important among the three groups of predictors. Both ESE and empathy predicted TSE positively (higher the ESE and empathy yielded higher TSE). As the result of addition of emotional variables, some of the individual and organizational variables (religiosity, seminar and school level) became insignificant. This instability in 
regression coefficients suggests that emotional variables play a role of moderating variables in the relationships between individual and organizational variables and TSE. Since the aim of our research was to examine to what extent each group of variables predicts TSE, rather than to test the inter-relationships between the variables, we did not test the moderating role of emotional variables. We suggest that a further research study should explore the inter-relationships between emotional and individual variables.

\section{Summary}

The results of bivariate correlations examinations show that TSE has the strongest correlations with emotional variables (ESE and empathy): high levels with of ESE and empathy are associated with high levels of TSE. Among the individual variables, job seniority is worth notion: teachers with five or more years of experience report higher TSE. Testing of model that predicted TSE by three groups of variables showed that the emotional variables have the highest ability to predict TSE. Individual variables were at the second place, while organizational variables were the weakest in prediction of TSE. Results also showed that while entering emotional variables to the model, the effects of some individual and organizational variables (religiosity, education and school level) became insignificant, suggesting that emotional variables play a role of moderators between individual and organizational variables and TSE and thus change the character of relationships between them

\section{Discussion}

While there is a wealth of studies that have investigated the relationship between teacher self-efficacy beliefs and the impact these may have on classroom practice, children's achievement and teachers' burnout, (Klassen et.al.2011) there is a clear need to place more emphasis on studying the sources, conditions and contributors to TSE (Gibbs \& Powell, 2011). Based on the above literature the purpose of the present study was to draw together external and internal variables that have been studied before in relation to teachers' self-efficacy beliefs (Knoblauch, \& Woolfolk Hoy, 2008) and to investigate their relative contribution to its prediction. We suggest that this kind of measurement can give us a more specific indication of what to emphasize in order to enhance TSE. We studied individual variables (level of religiosity, seniority, education institution and degree, special education training, age and gender), organizational variables (school type, integration of LD students in the class and number of students in class) and emotional variables (empathy and emotional self-efficacy).

The most significant finding in this initial investigation indicated that although all three groups of variables contribute to the prediction of teacher self -efficacy among teachers, emotional variables contributed the most. Empathy - meaning the ability to know another person's inner experience (Duan \& Hill, 1996), as well as emotional self-efficacy, which is a combination between emotional intelligence and general self-efficacy (Kirk, Schutte, \& Hine, 2008) seem to be powerful forces in the understanding of teacher self-efficacy (TSE). Few studies have suggested that different manners of relationship with parents and colleagues, and support from management are significant contributors to TSE (Friedman, 2003;. Skaalvik \& 
Skaalvik, 2007; Tschannen-Moran \& Woolfolk Hoy, 2006). Other studies more specifically indicated emotional intelligence as related to TSE ( Chan, 2004; Penrose et.al, 2007). However following Bandura's traditional theoretical framework (1986) most studies emphasized the search for the resources and contributors of TSE on mastery, experience, specific training and teaching resources (Brouwers, Evers \& Tomic, 2001; Knobloch \& Whittington, 2002; Watson, 2006), with no salient conclusion (Gibbs \& Powell, 2011; Klassen et. al, 2011) . Our findings add to the overall notion that in order to strengthen TSE and, thus contribute to teachers' overall well -being and functioning in school, there needs to be a greater emphasize on professional development of teachers as indicated by Stanovitch \& Jordan (2004), and more specifically, the development of their emotional abilities as suggested by others (Gibbs, 2003; Jennings \& Greenberg, 2009). Further it may suggest that when accepting new teachers to work, their emotional abilities should be considered as well.

Additional findings in this study suggested that traditional or religious subjects, females, experienced, primary and junior high school teachers, subjects with special training to work with LD pupils and teachers who integrate LD pupils in their classroom, reported higher levels of TSE than other subjects. These findings reinforce findings from other studies (Ho \& Hau, 2004; Klassen \& Chui, 2010), and emphasize the need for further research in order to better understand personal characteristics that may be related or effect TSE.

Although the sample of the present study was relatively large, all variables were based on self-reported measurements. We studied only three organizational variables, and perhaps not those that have more input on TSE. During the entire study we debated whether there is a clear difference between the measurements of TSE and ESE (emotional self-efficacy) although constructs are theoretically distinct. In addition we felt that the absence of qualitative measurements limits our ability to deepen our understanding of the relationship between emotional variables and TSE. There is a clear need for future research to address these limitations, and further explore those variables that contribute to teachers' professional lives.

\section{References}

Bandura, A. (1982). Self-efficacy mechanism in human agency. American Psychologist, 37(2), 122-147.

Bandura, A. (1986). The explanatory and predictive scope of self-efficacy theory. Journal of Social and Clinical Psychology, 4(3), 359-373. http://dx.doi.org/10.1521/jscp.1986.4.3.359

Bandura, A. (Ed.). (1997). self-efficacy: The exercise of control. New York: Freeman.

Betoret, F. D. (2009). Self-efficacy, school resources, job stressors and burnout among Spanish primary and secondary school teachers: A structural equation approach. Educational Psychology: An International Journal of Experimental Educational Psychology, 29(1), 45-68. http://dx.doi.org/10.1080/01443410802459234

Britner, S. L., \& Pajares, F. (2006). Sources of science self-efficacy beliefs of middle school 
students. Journal of Research in Science Teaching, 43(5), 485-499. http://dx.doi.org/10.1002/tea.20131

Brouwers, A., Evers, W. J. G., \& Tomic, W. (2001). Self-efficacy in eliciting social support and burnout among secondary-school teachers. . Journal of Applied Social, 31(7), 1474-1491.

Chan, D. (2008). Emotional intelligence, self-efficacy, and coping among Chinese prospective and in-service teachers in Hong Kong. Educational Psychology: An International Journal of Experimental Educational Psychology, 28(4), 397-408. http://dx.doi.org/10.1080/01443410701668372

Chan, D. W. (2003). Multiple intelligence and perceived self-efficacy among Chinese secondary school teachers in Hong Kong. Personality and Individual Differences, 23(5), 521-533. http://dx.doi.org/10.1080/0144341032000123778

Chan, D. W. (2004). Perceived emotional intelligence and self-efficacy among chinese secondary school teachers in Hong Kong. Personality and Individual Differences, 36, 1781-1795. http://dx.doi.org//10.1016/j.paid.2003.07.007

Davis, M. H. (1983). Measuring individual differences in empathy: Evidence for a multidimensional approach.. Journal of Personality and Social Psychology, 44, 113-136.

Freidman, I. A. (2003). . Self-efficacy and burnout in teaching: The importance of interpersonal-relations efficacy. Social Psychology of Education, (6), 191-215.

Friedman, I. A., \& Kass, E. (2002). Teacher self-efficacy: A classroom-organization conceptualization. Teaching and Teacher Education, 18, 675-686. http://dx.doi.org//10.1016/S0742-051X(02)00027-6

Gibbs, C. (2003). Explaining effective teaching: Self-efficacy and thought control of action. Journal of Educational Enquiry, 4, 1-14.

Gibbs, S., \& Powell, B. (2011). Teacher efficacy and pupil behavior: The structure of teachers' individual and collective beliefs and their relationship with numbers of pupils excluded from school . British Journal of Educational Psychology, 1-21. http://dx.doi.org/10.1111/j.2044-8279.2011.02046

Guskey, T. R., \& Passaro, P. D. (1994). Teacher efficacy: A study of construct dimensions. American Education Research Journal, 31(3), 627-643.

Ho, I. T., \& Hau, K. T. (2002). Australian and chinese teacher efficacy: Similarities and differences in personal instruction, discipline, guidance efficacy and beliefs in external determinants. Teaching and Teacher Education, 20, 313-323. http://dx.doi.org//10.1016/j.tate.2003.09.009

Jennings, P. A., \& Greenberg, M. T. (2009). The prosocial classroom: Teacher social and emotional competence in relation to student and classroom outcomes. Review of Educational Research, 79(1), 491-525. http://dx.doi.org/10.3102/0034654308325693

Kirk, B. A., Schutte, N. S., \& Hine, D. W. (2008). Development and preliminary validation of 
an emotional self-efficacy scale. Personality and Individual Differences, (45), 432-436. http://dx.doi.org/10.1016/j.paid.2008.06.010

Klassen, R. M., Tze, V. M. C., Betts, S. M., \& Gordon, K. A. (2011). Teacher efficacy research 1998-2009: Signs of progress or unfulfilled promise? Educational Psychology Review, 23(1), 21-43. http://dx.doi.org/10.1007/s10648-010-9141-8

Klassen, R. M., \& Chui, M. M. (2010). Effects on teachers' self-efficacy and job satisfaction:Teacher gender, years of experience, and job stress. Journal of Educational Psychology, 102(3), 741-756. http://dx.doi.org/10.1037/a0019237

Knoblauch, D., \& Woolfolk Hoy, A. (2008). "Maybe I can teach those kids." the influence ofcontextual factors on student teachers' efficacy beliefs. Teaching and Teacher Education, 24, 166-179. http://dx.doi.org/10.1016/j.tate.2007.05.005

Knobloch , N. A., \& Whittington, M. S. (2002). Novice teachers' perceptions of support, teacher preparation quality, and student teaching experience related to teacher efficacy, Journal of Vocational Education Research, 27(3), 331-341. http://dx.doi.org/10.5328/JVER27.3.331

Labone, E. (2004). Teacher efficacy: Maturing the construct through research in alternative paradigms. Teaching and Teacher Education, 20, 341-359. http://dx.doi.org//10.1016/j.tate.2004.02.013

Penrose, A., Perry, C., \& Ball, I. (2007). Emotional intelligence and teacher self -efficacy: The contribution of teacher status and length of experience. Issues in Educational Research, $17,20-34$.

Saracaloğlu, A.S. \& Yenice, N. (2009). Investigating the self-efficacy beliefs of science and elementary teachers with respect to some variables. Journal of Theory and Practice in Education, 5(2), 244-260.

Skaalvik, E. M., \& Skaalvik, S. (2007). _ Dimensions of teacher self-efficacy and relations with strain factors, perceived collective teacher efficacy, and teacher burnout. 611-625. Journal of Educational Psychology, , 611-625. http://dx.doi.org/10.1037/0022-0663.99.3.611

Skaalvik, E. M., \& Skaalvik, S. (2010). Teacher self-efficacy and teacher burnout: A study of relations. 26. Teaching and Teacher Education, 26, 1059-1069. http://dx.doi.org/10.1016/j.tate.2009.11.001

Somech , A., \& Drach-Zahavy, A. (2000). Understanding extra-role behavior in schools: The relationships between job satisfaction, sense of efficacy, and teachers' extra-role behavior. Teaching and Teacher Education, 16, 649-659.

Stanovitch , P., \& Jordan, A. (2004). Inclusion as professional development. , Exceptionality Education Canada, 14(2,3), 169-188.

Tschannen-Moran, M., \& McMaster, P. (2009). Sources of Self-Efficacy: Four professional development formats and their relationship to Self-Efficacy and implementation of a new 


\section{Macrothink}

Journal of Studies in Education

ISSN 2162-6952 2013, Vol. 3, No. 3

teaching strategy. The Elementary School Journal, 110(2) 228-245. http://dx.doi.org/10.1086/605771

Tschannen-Moran, M., \& Woolfolk Hoy, A. (2001). Teacher efficacy: Capturing an elusive construct. . Teaching and Teacher Education, 17, 783-805.

Tschannen-Moran, M., Woolfolk Hoy, A., \& Hoy, W. K. (1998). Teacher efficacy: Its meaning and measure. Review of Educational Research, 68, 202-248. http://dx.doi.org/10.3102/00346543068002202

Tschannen-Moran, M., \& Woolfolk Hoy , A. (2007). The differential antecedents of self-efficacy beliefs of novice and experienced teachers. Teaching and Teacher Education, 23(6), 944-956. http://dx.doi.org/10.1016/j.tate.2006.05.003

Usher, E. L., \& Pajares, F. (2008). Sources of self-efficacy in school: Critical review of the literature and future directions. Review of Educational Research, 78(4), 751-796. http://dx.doi.org/10.3102/0034654308321456

Watson, G. (2006). Technology professional development: Long-term effects on teacher self-efficacy. Journal of Technology and Teacher Education, 14(1), 151-166.

Woolfolk Hoy, A., \& Burke-Spero, R. (2005). Changes in teacher efficacy during the early years of teaching: A comparison of four measures. Teaching and Teacher Education, 21, 343-356.

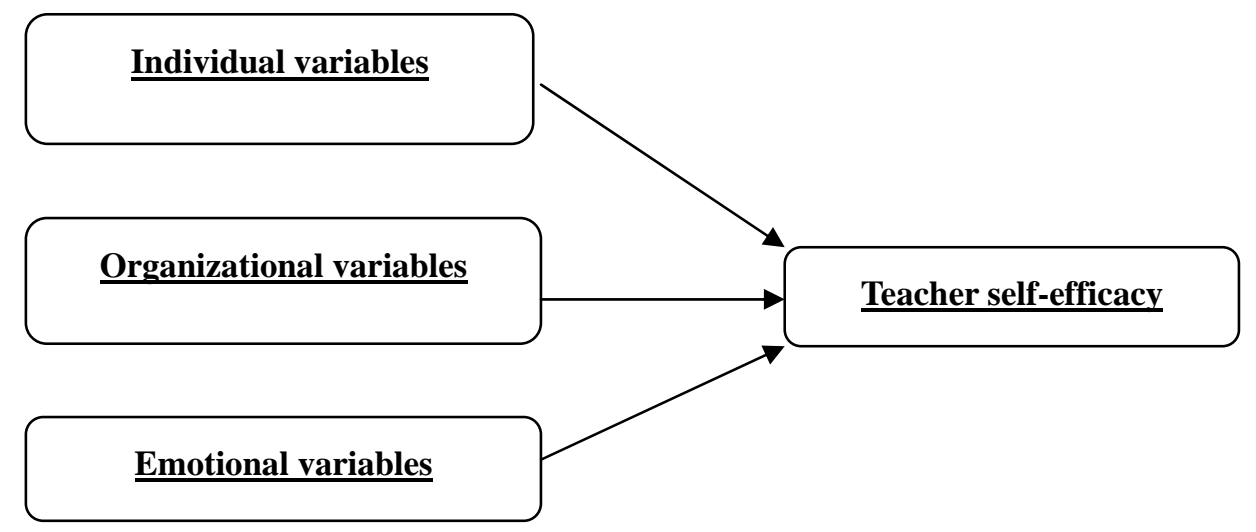

Figure 1. A theoretical model of prediction of TSE by individual, organizational and emotional variables 
Table 1. Pearson correlations between the research variables

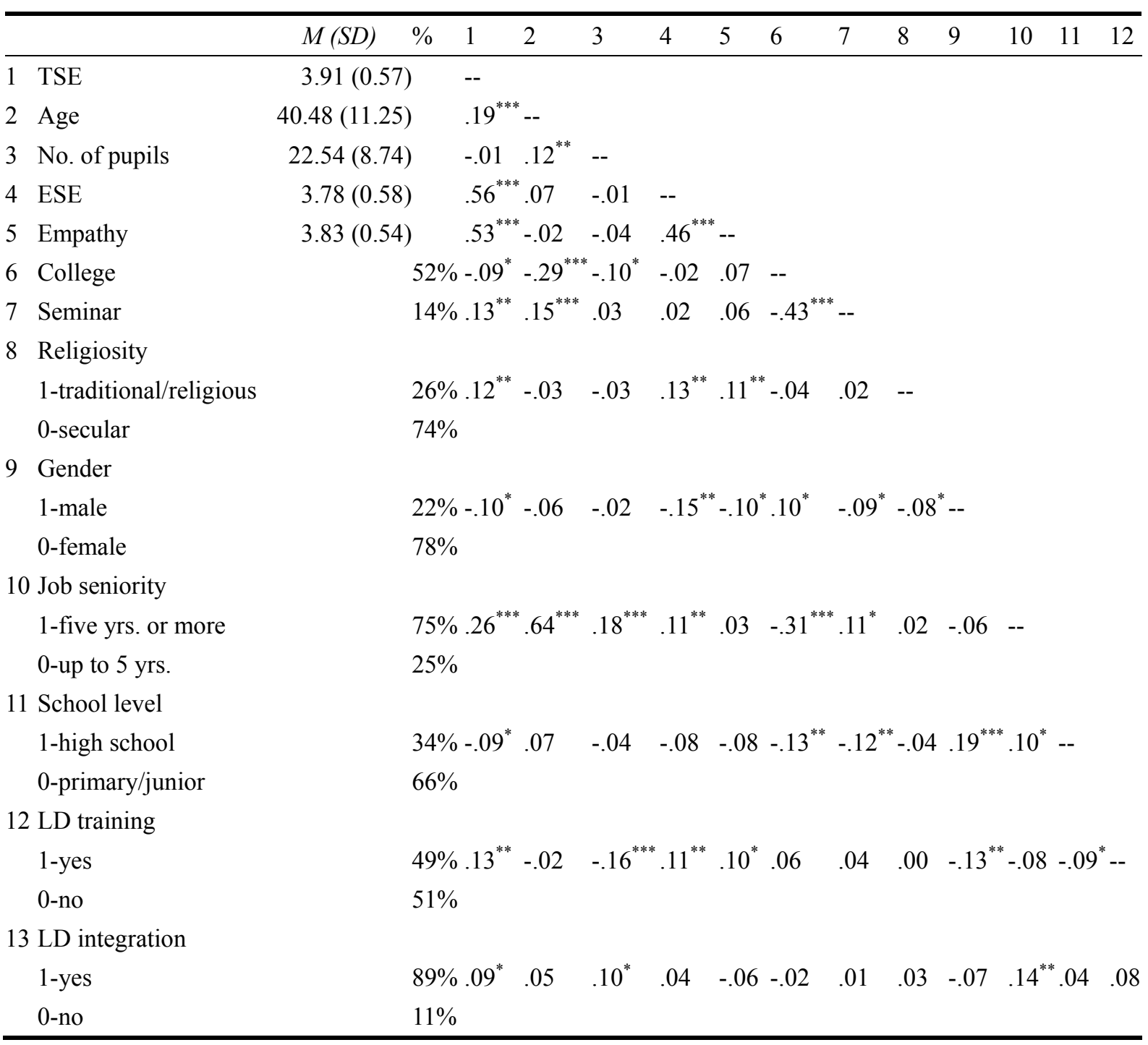

${ }^{*} p<.05,{ }^{* *} p<.01,{ }^{* * *} p<.001$ 


\section{Macrothink}

Journal of Studies in Education

ISSN 2162-6952

2013, Vol. 3, No. 3

Table 2. Multiple regression using forced entry methods for prediction of TSE by individual, organizational and emotional variables

\begin{tabular}{|c|c|c|c|c|c|c|c|c|c|}
\hline & \multicolumn{3}{|l|}{ Step $1^{1}$} & \multicolumn{3}{|l|}{ Step $2^{2}$} & \multicolumn{3}{|l|}{ Step $3^{3}$} \\
\hline & $\mathrm{B}$ & SE ( B) & $\beta$ & $\mathrm{B}$ & SE ( B) & $\beta$ & $\mathrm{B}$ & SE ( B) & $\beta$ \\
\hline $\begin{array}{l}\text { Religiosity } \\
\text { (1-traditional/religious) }\end{array}$ & $0.14^{*}$ & 0.06 & 0.10 & $0.13^{*}$ & 0.06 & 0.10 & 0.00 & 0.05 & 0.00 \\
\hline $\begin{array}{l}\text { Job seniority } \\
\text { (1-five yrs. or more) }\end{array}$ & $0.33^{* * *}$ & 0.08 & 0.25 & $0.34^{* * *}$ & 0.08 & 0.25 & $0.20^{* *}$ & 0.06 & 0.15 \\
\hline College & 0.06 & 0.06 & 0.05 & 0.03 & 0.06 & 0.02 & -0.05 & 0.05 & -0.05 \\
\hline Seminar & $0.19^{*}$ & 0.08 & 0.11 & $0.17^{*}$ & 0.08 & 0.10 & 0.10 & 0.06 & 0.06 \\
\hline $\begin{array}{l}\text { LD training } \\
\text { (1-yes) }\end{array}$ & $0.16^{* *}$ & 0.05 & 0.14 & $0.14^{* *}$ & 0.05 & 0.12 & $0.10^{*}$ & 0.04 & 0.08 \\
\hline $\begin{array}{l}\text { School level } \\
\text { (1-high school) }\end{array}$ & & & & $-0.12^{*}$ & 0.06 & -0.10 & -0.07 & 0.04 & -0.06 \\
\hline Number of pupils & & & & 0.00 & 0.00 & -0.06 & 0.00 & 0.00 & -0.04 \\
\hline $\begin{array}{l}\text { LD integration } \\
\text { (1-yes) }\end{array}$ & & & & 0.09 & 0.08 & 0.05 & $0.17^{* *}$ & 0.06 & 0.09 \\
\hline ESE & & & & & & & $0.37^{* * *}$ & 0.04 & 0.36 \\
\hline Empathy & & & & & & & $0.39^{* * *}$ & 0.04 & 0.36 \\
\hline Controls: & & & & & & & & & \\
\hline Age & 0.00 & 0.00 & 0.02 & 0.00 & 0.00 & 0.02 & 0.00 & 0.00 & 0.05 \\
\hline Gender (1-male) & -0.06 & 0.07 & -0.04 & -0.04 & 0.07 & -0.03 & 0.05 & 0.05 & 0.03 \\
\hline $\begin{array}{l}{ }^{*} p<.05,{ }^{* *} p<.01,{ }^{* * *} p<.00 \\
{ }^{1} R^{2}=.11 \text { for Step } 1 \text { (indi }\end{array}$ & dual var & les) & & & & & & & \\
\hline $\begin{array}{l}{ }^{2} R^{2}=.12 ; \Delta R^{2}=.01(p>.0 \\
{ }^{3} R^{2}=.48 ; \Delta R^{2}=.36(p<.0\end{array}$ & $\begin{array}{l}\text { for Step } \\
\text { 1) for Ste }\end{array}$ & $\begin{array}{l}\text { (individ } \\
3 \text { (indivi }\end{array}$ & $\begin{array}{l}\text { and } \\
1, \text { or }\end{array}$ & izatio & zariable & 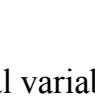 & & & \\
\hline
\end{tabular}




\section{Individual variables:}

Religiosity (1-traditional/religious) (.00)

Job seniority (1-five years or more) $\left(.15^{* *}\right)$

Education (seminar: .06, college: -.05)

Training to work with students with LD (1-yes) $\left(.08^{*}\right)$

Controls:

\section{Organizational variables:}

School level (1-high school) (-.06)

Number of pupils (-.04)

\section{Emotional variables:}

Emotional self-efficacy $\left(.36^{* *}\right)$

Note: In parentheses - standardized regression coefficients $(\beta)$

Figure 2. Summary of effects of individual, organizational and emotional variables on TSE (last step) 